\title{
Nonlinear 3D Model of Double Shear Lap Tests for the Bond of Near-surface Mounted FRP Rods in Concrete Considering Different Embedment Depth
}

\author{
Yanuar Haryanto ${ }^{1,2}$, Hsuan-Teh Hu${ }^{1,3^{*}}$, Ay Lie Han ${ }^{4}$ Fu-Pei Hsiao ${ }^{1,5}$, Charng-Jen Teng ${ }^{1}$, \\ Banu Ardi Hidayat ${ }^{1,4}$, Laurencius Nugroho ${ }^{1}$ \\ ${ }^{1}$ Department of Civil Engineering, College of Engineering, National Cheng Kung University, No. 1 University Road, Tainan, 701, Taiwan \\ (R.O.C) \\ ${ }^{2}$ Department of Civil Engineering, Faculty of Engineering, Jenderal Soedirman University, Jln. Mayjen. Sungkono KM 5, Blater, \\ Purbalingga, 53371, Indonesia \\ ${ }^{3}$ Department of Civil and Disaster Prevention Engineering, College of Engineering and Science, National United University, No. 2, Lien \\ Da, Nan Shih Li, Miaoli, 36063, Taiwan (R.O.C) \\ ${ }^{4}$ Department of Civil Engineering, Faculty of Engineering, Diponegoro University, Jln. Prof. Soedarto, Tembalang, Semarang, 50275, \\ Indonesia \\ ${ }^{5}$ National Center for Research on Earthquake Engineering, 200 Sec. 3, Xinhai Road, Taipei, 10668, Taiwan (R.O.C) \\ * Corresponding author, e-mail: hthu@ncku.edu.tw
}

Received: 06 October 2020, Accepted: 02 March 2021, Published online: 06 April 2021

\begin{abstract}
The utilization of near-surface mounted Fiber Reinforced Polymer (FRP) reinforcement as a method of strengthening in reinforced concrete structures has increased considerably in recent years. Moreover, the application of double-shear lap tests for this reinforcement method leads to the achievement of a local bond-slip behavior in a bonded joint. This research, therefore, focused on 3-D modeling of this type of test to suitably characterize the bond mechanics between FRP rods and concrete at various embedment depth. The use of different alternatives to represent the interface between the FRP rod and concrete were analyzed after which a comparison was drawn between the numerical finite element (FE) simulations and experimental measurements. The results showed the prediction of the load-slip corresponded with the data obtained from the experiment. Finally, the proposed model has the ability to express the relationship between the penalty stiffness parameters in shear direction $K_{s s}=\left(K_{t t}\right)$ and the embedment depth of FRP rods.
\end{abstract}

Keywords

FE model, fiber reinforced polymer, concrete, interfacial bond, double shear lap test

\section{Introduction}

The increment in load for a structure as well as aging and environmental effects have the ability to reduce its capacity to sustain new loads [1]. It has, however, been reported that an increment in the capacity of an affected structure through the use of different methods of strengthening is considered to be more rational and economical compared to the demolition and subsequent construction of new ones [2]. Moreover, Fiber Reinforced Polymer (FRP) composite has become popular compared to other strengthening materials such as steel due to its superior thermomechanical performances $[3,4]$. The FRP is commonly applied using NearSurface Mounted (NSM) which involves the introduction of FRP rods or strips into the surface grooves. These are usually cut along the concrete's cover through the process of flexural strengthening [5-7] on the tension side or shear strengthening $[8,9]$ in the web to ensure an increment in the load-carrying capacity. This method is beneficial due to the ease with which it can be installed, better bonding in comparison with the conventional method, provide more protection from natural hazards, and ensure the structure is less exposed to accidental damage [10].

An important aspect of using the NSM technique to improve structural performance is the bond behavior. This is due to the fact, that the popular modes of failure are the bond loss both at the adhesive layer and in the interfaces between FRP rod and adhesives or adhesives and concrete. Therefore, the reinforced elements' ultimate capacity depends on the behavior of the bond. Several series of 
test have been conducted up to the present time through the application of direct and beam pull-out tests to analyze the effect of important variables in the NSM method. The direct pull-out test involves the embedment of NSM rods on one or more sides of a square/rectangular concrete block [11-14] as observed in the double shear lap test in Fig. 1 [15]. The beam pull-out test specimen, however, has two concrete blocks which are connected using a steel hinged at the top and a FRP rod embedded in the concrete's cover on the blocks' lower face [16, 17]. These methods have both merits and demerits, and this has led to several attempts towards ensuring the reduction or total removal of the demerits [18, 19].

Several experimental studies have been developed up to the present time but due to a higher number of variables related to NSM bond performance in comparison with the externally-bonded FRP systems, different FRP which are available on commercial scale, and epoxy products, there is a need for a further experimental and numerical investigation to completely analyze a bond model of NSM-FRP rods. This study was mainly conducted to develop a comprehensive nonlinear three-dimensional finite element (FE)

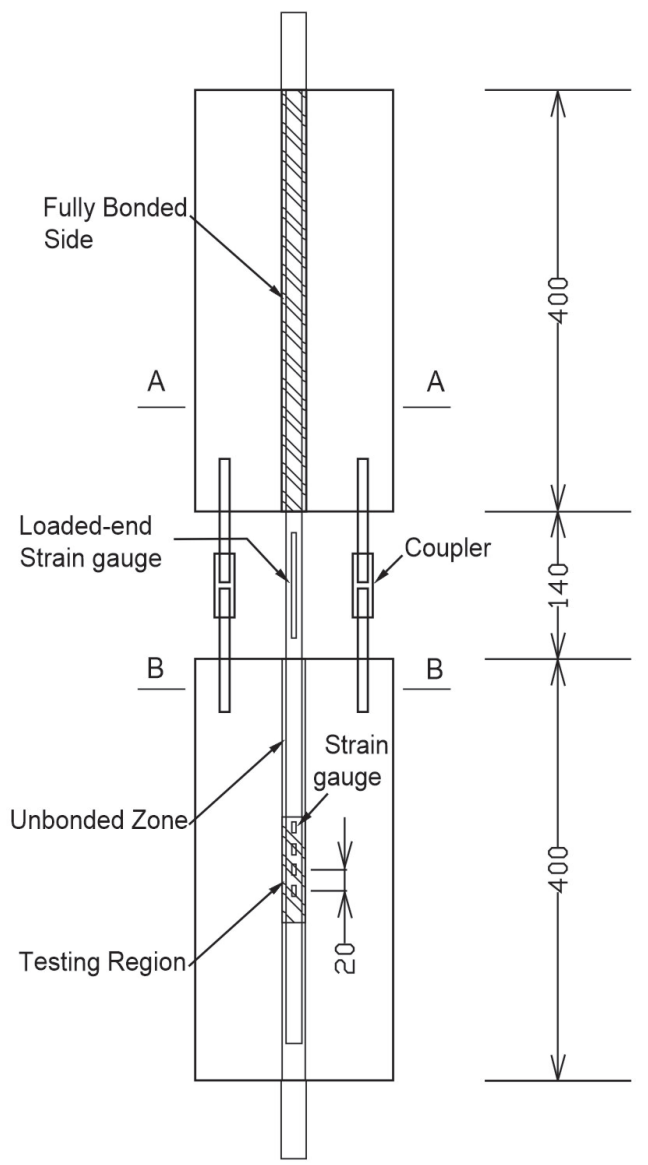

Fig. 1 Double shear lap test model through the use of software code to accurately simulate the direct pull-out tests with double shear lap testing. The purpose was to suitably characterize the bond mechanics between concrete and FRP rods and this involved placing special emphasis on modeling the interface behavior observed to be existing among NSM FRP rod and concrete through the adjustment of the behavior of contact interaction. Moreover, different embedment depths were also considered due to the challenges frequently encountered by engineers when the required standard mandated by ACI 440.2R-08 [20] is not achieved in the structural frames of buildings on the field [21].

\section{Summary of the experimental program}

The preparation and testing of double shear lap specimens were conducted under pull-out tension load in line with the experimental study of Budipriyanto et al. [22] to measure the ultimate failure of FRPs embedded in the concrete as depicted in Fig. 2 [22, 23].

The experimental was set-up to ensure the bonded FRP rod fails due to the loss of bond by assuming it closely approaches the steel reinforcing bars bond with similar size and bond-length set at $100 \mathrm{~mm}$. Moreover, the research conducted by Caro et al. [24] showed bond-length as part of the important variables influencing the mode of failure. This involved the arrangement of the tensile pull-off bar with $25 \mathrm{~mm}$ diameter as one solid element during casting to achieve the stability of the test specimen and centricity of the tensile force applied as shown in Figs. 3(a) and 3(b). Moreover, the universal testing machine (UTM) grips were appropriately arranged after which there was cutting of pull-off bar and placement of precision instruments as indicated in Fig. 3(c). A centric tensile load was applied by the UTM to the $25 \mathrm{~mm}$ bars and there was an increment of $20 \mathrm{~N} / \mathrm{sec}$ with close observation of the bonded FRP rods when the loading was increased in a monotonic manner.

The rods' embedded depth affects the bond it has with epoxy resin and concrete while its relative position to the surface of the concrete also influences distribution of stress. Higher values of stress were observed to have been induced close to the rod end based on the strains accumulated during the tensile test [25]. However, the possible failure modes include concrete failure in shear and loss of bond between the concrete and epoxy interface as well as the rod and epoxy. The failures attributed to FRP rod in tension were ignored in this experiment based on the material's high tensile strength. The FRP rods' positions relative to the surface of the concrete were classified into 

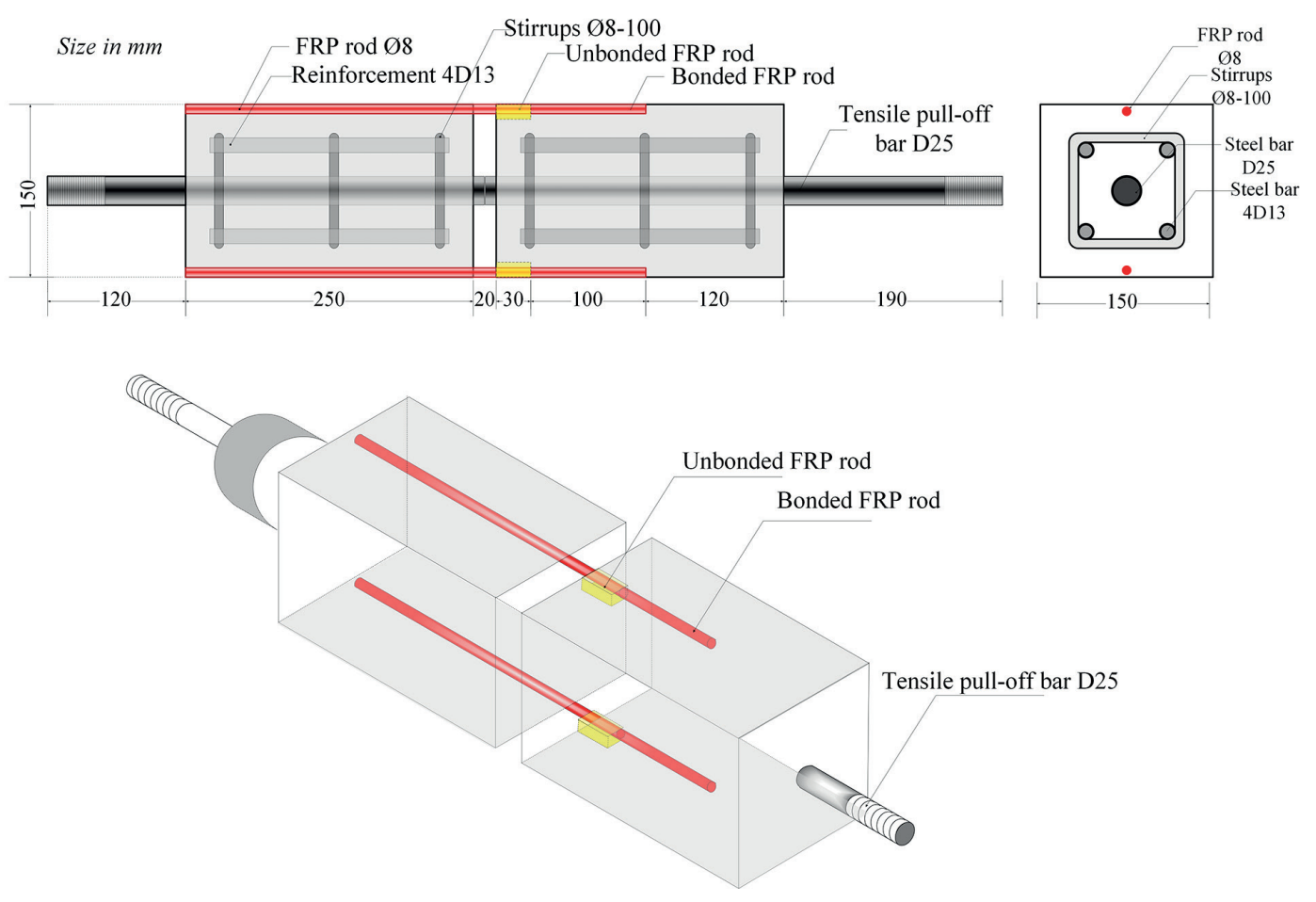

Fig. 2 Experimental of FRP rod bond behavior



(a) Set up

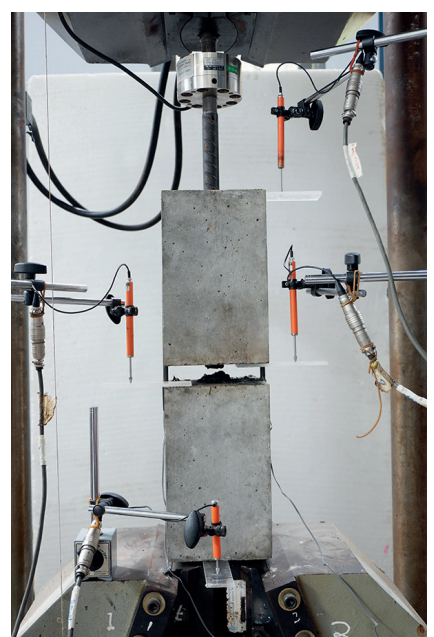

(b) FRP rod

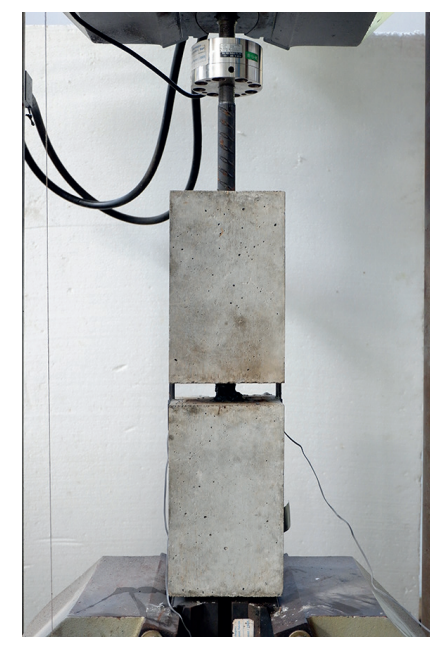

(c) Cutting of pull-off bar

Fig. 3 Assemblage and pull-off bar cutting

three types as indicated in Fig. 4. Furthermore, the application of RTF specimens was based on the code [20] at $14 \mathrm{~mm}$ embedded depth which is known as the "full-embedded". The code, however, requires the depth to be at a minimum of 1.5 of the rod diameters. Meanwhile, the RTE specimens had $75 \%$ contact area having $10 \mathrm{~mm}$ groove depth and classified as edge-embedded while the RTH specimens had an interface which is one-half of the rod circumference and a $6 \mathrm{~mm}$ deep groove which is classified as half-embedded. There was preparation of four specimens for each category.

\section{Finite element model}

\subsection{Model description}

Three models of FE were developed through the use of the finite element software, ABAQUS [26], after which a comparison was made between the values predicted and those obtained from the double shear lap specimens tested in the previous section. The models consist of nonlinear constitutive laws for the concrete, steel, and FRP rod materials and the contact simulation behavior between the FRP rod and surfaces of the concrete. They were created based on the three embedded depths of the FRP rod which 




(a) RTF

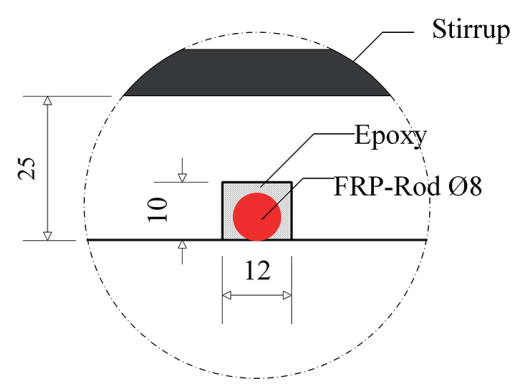

(b) RTE

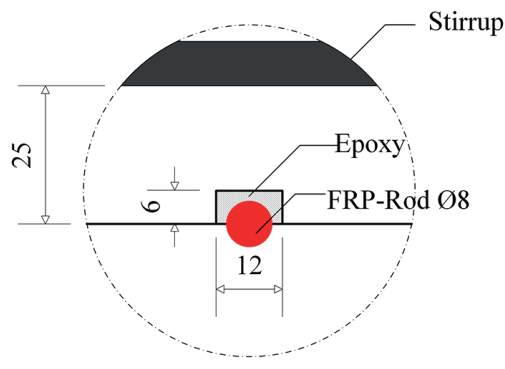

(c) RTH

Fig. 4 Specimen classification
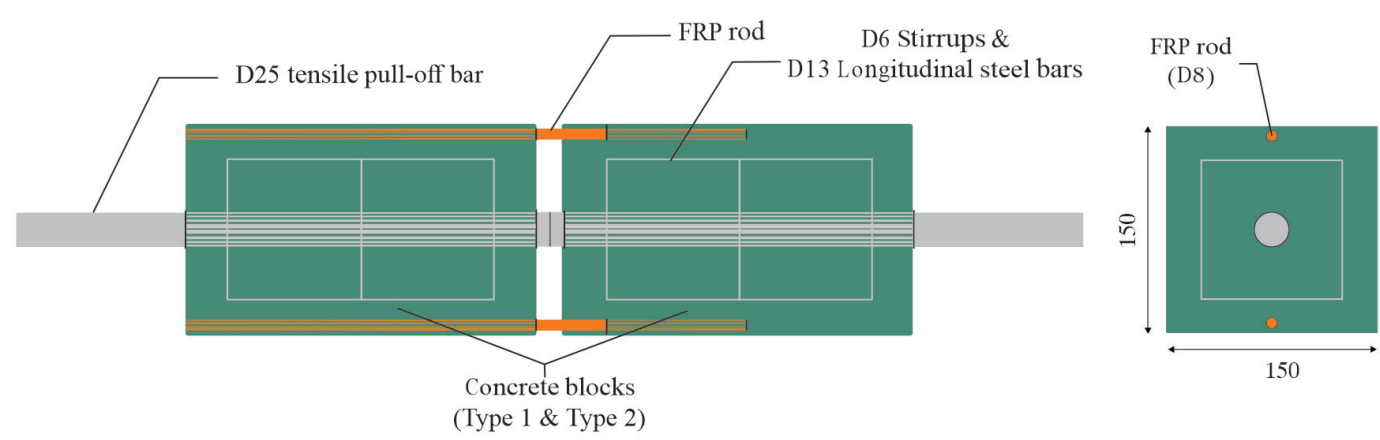

Fig. 5 FE model developed for full-embedded double shear lap specimen

are full-embedded, edge-embedded, and half-embedded. All the components and settings were built according to the experimental settings and the full-embedded model was selected for subsequent introduction for better understanding as shown in Fig. 5.

The model included concrete blocks, FRP rods, stirrups, longitudinal reinforcements, and tensile pull-off bars. The FRP rods were placed based on the length of the grooves to create two types of concrete blocks. The first type has a $250 \mathrm{~mm}$ grooves on its opposite sides while the second has $100 \mathrm{~mm}$. The FRP rod has an $8 \mathrm{~mm}$ diameter and $400 \mathrm{~mm}$ length and connected the two concrete blocks by filling their grooves as shown in Fig. 6 .

Multiple types of elements were employed to model the three specimens. This involved the use of 3D 8-noded hexahedral (brick) elements having decreased integration (C3D8R) to avoid shear locking effect in modeling concrete blocks, FRP rods, and the tensile pull-off bars. This type of element comes with 3 degrees of freedom in each node which are translations in the $\mathrm{X}, \mathrm{Y}$, and $\mathrm{Z}$ directions. Meanwhile, 2-noded truss elements (T3D2) were used to model the reinforcements. This type of element also has 3 degrees of freedom in each node which are translations in the $\mathrm{X}, \mathrm{Y}$, and $\mathrm{Z}$ directions of the global coordinates system. Moreover, to limit the computation time, meshing was performed without a mesh independency test. The summary of the elements is, however, presented in Fig. 7.

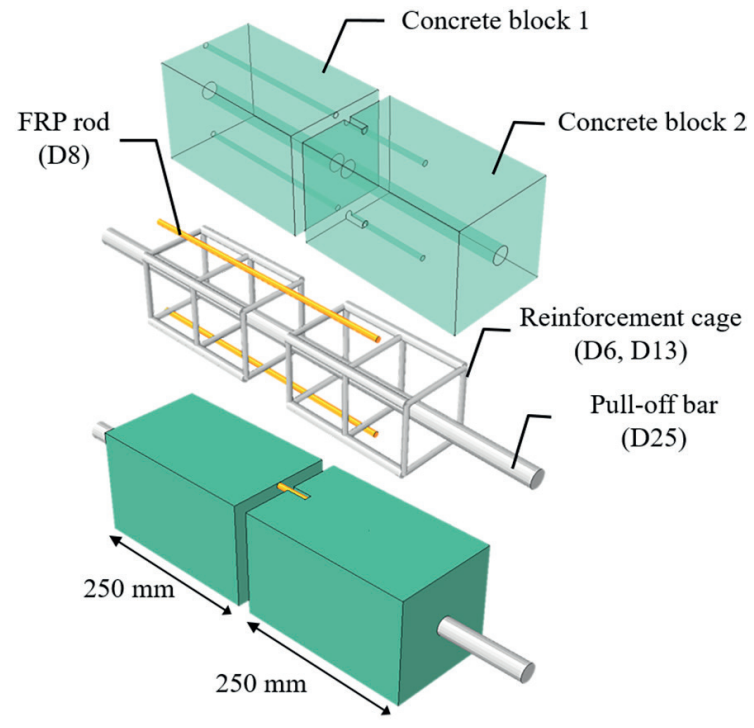

Fig. 6 Geometry of double shear lap test model

\subsection{Material properties and constitutive laws}

The same materials' properties of the different components in the experimental specimens were found to be applied in developing the FE models. Meanwhile, the concrete material plasticity was determined through the application of the Concrete Damage Plasticity (CDP) model designed by combining isotropic tensile and compressive plasticity with continuum damage mechanics and scalar damaged elasticity concepts to ensure proper representation of the concrete's inelastic behavior [27]. The two major failure 


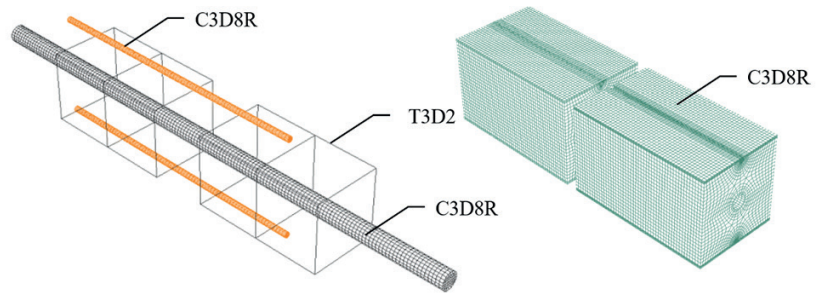

Fig. 7 Element types

mechanisms for concrete materials, according to the basic assumptions of damage plasticity model, include tensile cracking and compressive crushing.

An average concrete compressive strength of $36.37 \mathrm{MPa}$ was obtained on the testing day and the modulus of elasticity of the material was considered to be $E_{c}=4700 \sqrt{f_{c}^{\prime}}$ based on ACI 318-14 [28] while the Poisson's ratio was recorded to be 0.2 . Concrete's nonlinear behavior in compression have been simulated in several previous studies such as Hognestad parabola [29], Vecchio and Collins [30], and Hsu [31]. An experimental data was, however, applied in this study as shown in Fig. 8.

The two parts of the concrete's uniaxial stress-strain behavior in tension are indicated in Fig. 9 and the first involved showing a linear elastic behavior until the concrete tensile strength $f_{t}$ while the second was initiated with cracking and its propagation in the concrete material under tension which is demonstrated by a descending branch in the diagram. This phase's behavior was modeled through the application of a softening procedure using linear, bilinear, or nonlinear stress-strain relationships [32]. For the purpose of this analysis, a linear behavior was applied with the ultimate cracking strain presumed to be 0.003 while the minimum tensile stress was made close to zero to avoid the potential convergence problem and the ultimate tensile strength of the concrete was estimated to be $f_{t}^{\prime}=0.33 \sqrt{f_{c}^{\prime}}[33,34]$.

The other parameters needed for the definition of the CDP model are the dilation angle $(\psi)$, plastic potential eccentricity of concrete $(e)$, ratio of compressive stress in the biaxial to the uniaxial state $\left(\sigma_{b 0} / \sigma_{c 0}\right)$, shape factor $\left(K_{c}\right)$ of the yielding surface in the deviatory plane, and the viscosity. For $e, \sigma_{b 0} / \sigma_{c 0}$ and $K_{c}$ are using the suggested value, while the values of $\psi$ and viscosity parameter refer to the study conducted by Raza et al. [34].

The steel material's modulus of elasticity and yield strength were $200 \mathrm{GPa}$ and $400 \mathrm{MPa}$, respectively in the experiment while the Poisson's ratio was estimated at 0.2 and the nonlinear property was presumed to be elastic-perfectly plastic [35] as shown in Fig. 10. The FRP

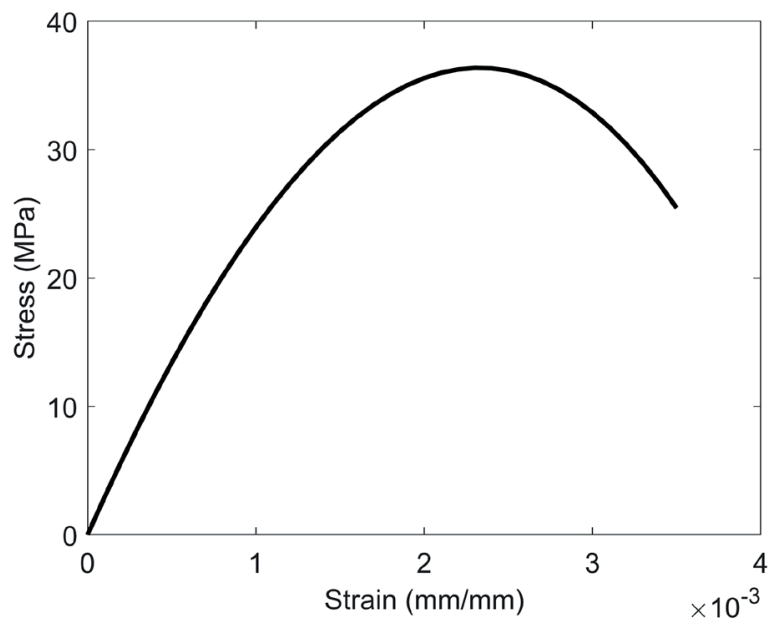

Fig. 8 Concrete compressive stress-strain curve

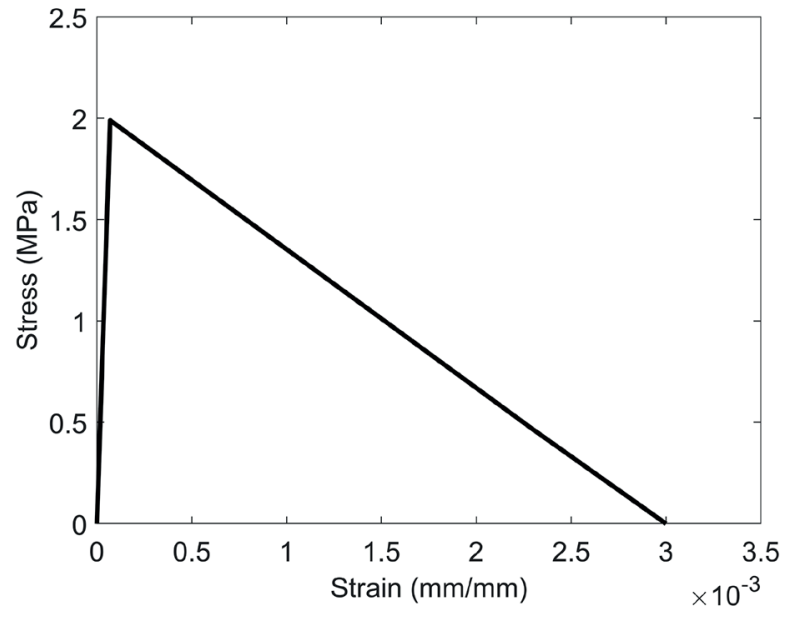

Fig. 9 Concrete uniaxial tensile stress-strain behavior and its softening branch assumptions

rod mechanical properties are obtained from PT. SIKA Indonesia. The attained modulus of elasticity and tensile strength are $148 \mathrm{GPa}$ and $3100 \mathrm{MPa}$, respectively. In addition, the Poisson's ratio for the FRP was estimated to be 0.33 while FRP rod's nonlinear response was presumed to be elastic-fully plastic [35] as demonstrated in Fig. 10.

\subsection{Contact interaction}

The contact surfaces were assumed to be perfectly bonded in the model and the built-in tie function in the program was selected to represent this behavior in the first stage of the study to ensure the stimulation of the interaction behavior among the concrete and tensile pull-off bar as well as the concrete and FRP rod. Moreover, tensile pulloff bars were set as rigid bodies to ensure higher stiffness compared to the concrete while the contact settings between the concrete and steel bars were represented by the built-in embedded region function in the program. 


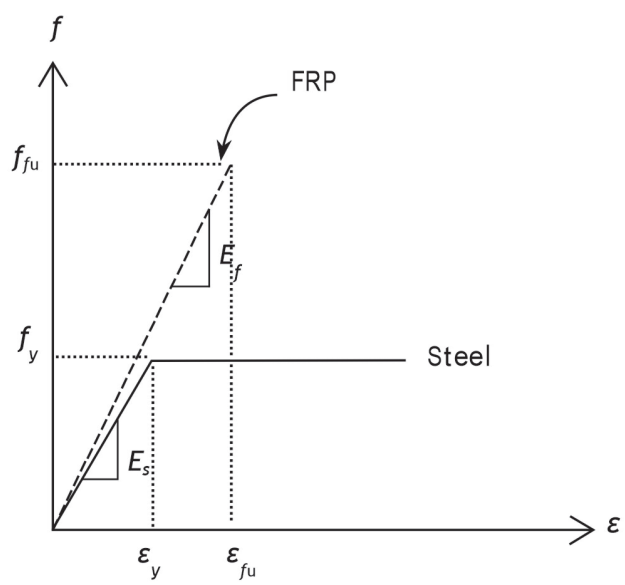

Fig. 10 Stress-strain curves for steel material and FRP [35]

Finally, since the macroscopic properties such as stiffness and strength of the epoxy resin as the adhesive material are not available, it will be more appropriate to model the interaction behavior among the concrete and FRP rod using cohesive contact behavior at the second stage of the study [26]. The elastic response of the cohesive contact behavior was explained using an uncoupled traction-relative displacement law with the three traction stresses considered shown in Eq. (1).

$$
\left\{\begin{array}{l}
t_{n} \\
t_{s} \\
t_{t}
\end{array}\right\}=\left[\begin{array}{ccc}
K_{n n} & 0 & 0 \\
0 & K_{s s} & 0 \\
0 & 0 & K_{t t}
\end{array}\right]\left\{\begin{array}{l}
u_{n} \\
u_{s} \\
u_{t}
\end{array}\right\},
$$

where $t_{n}, t_{s}$, and $t_{t}$ indicates normal and two shear traction stress components, respectively, $u_{n}, u_{s}$, and $u_{t}$ represent the corresponding separations while $K_{n n}, K_{s s}$, and $K_{t t}$ are the penalty stiffness parameters.

\section{Results and discussion}

\subsection{Model validation}

The main idea to develop a perfect bond model was to represent, in a simplified way, the pull-out behavior, using previous results on double shear lap specimens. The predicted perfect bond model and measured load-slip responses for the tested specimens are demonstrated in Fig. 11.

The predictions made by the models with a perfect bond assumption for failure load in the numerical simulation showed a reasonable agreement with an average of $7.55 \%$ disparity as shown in Table 1 . However, the results obtained from the models depicted greater stiffness and this was explained by the assumption of a perfect bond which ignores the bond-slip relationship, consequently, increasing the models' stiffness.

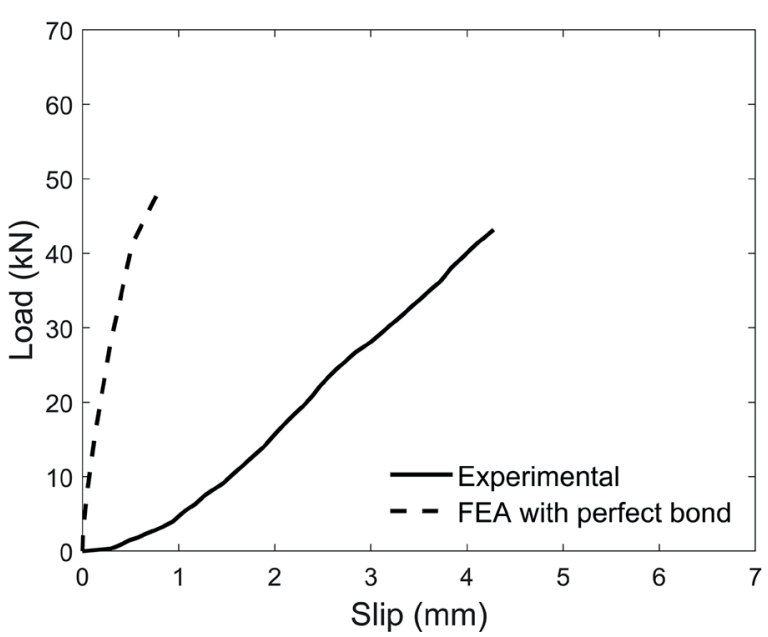

(a) RTH model

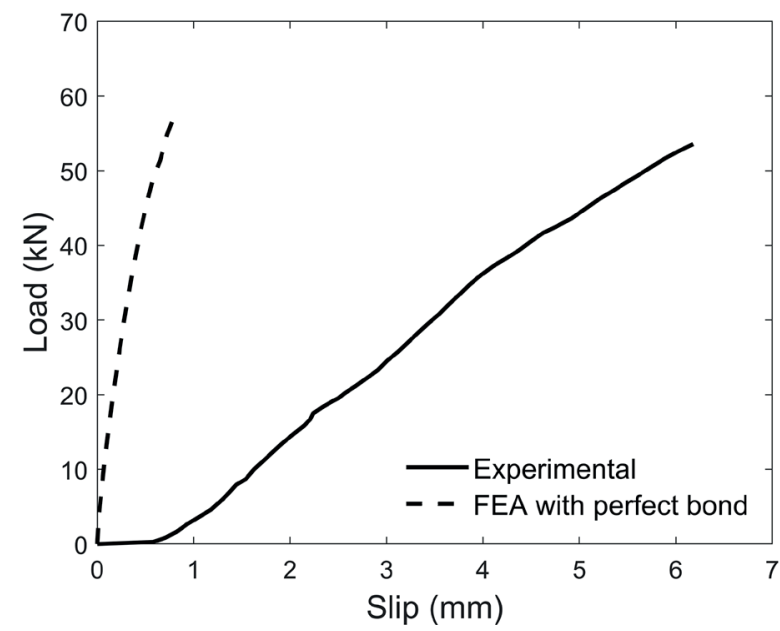

(b) RTE model

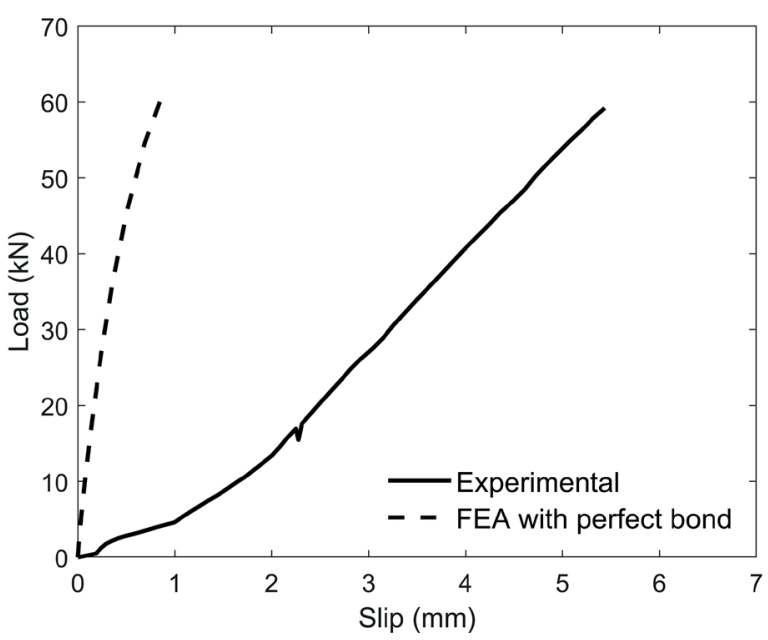

(c) RTF model

Fig. 11 Load versus slip for a perfect bond model

The main objective of the simulation conducted with the use of cohesive contact behavior to model surface interaction between concrete and FRP rod was to represent the load-slip behavior of the double shear lap tests 
Table 1 Experimental results vs FE perfect bond model

\begin{tabular}{lccc}
\hline Specimen & $\mathrm{P}_{\mathrm{u}(\mathrm{Exp})}(\mathrm{kN})$ & $\mathrm{P}_{\mathrm{u}(\mathrm{FE}-\mathrm{PB})}(\mathrm{kN})$ & Difference $(\%)$ \\
\hline RTH & 43.15 & 48.92 & 11.79 \\
RTE & 53.57 & 57.37 & 6.62 \\
RTF & 59.21 & 61.83 & 4.23 \\
\hline
\end{tabular}

more accurately. Moreover, in the second phase of the simulation, the same value of penalty stiffness parameters was presumed for shear direction and this reduced the requested parameters to two. Therefore, setting $K_{s s}=\left(K_{t t}\right)$ as the independent variable and $K_{n n}$ as the control variable for the FE analysis showed the change of $K_{s s}=\left(K_{t t}\right)$ has a great influence on the simulation results. Fig. 12 further shows the stiffness of the load-slip curve increases and move closer to the value obtained for the perfect bond model as $K_{s s}=K_{t t}$ moves higher.

Meanwhile, the use of $K_{n n}$ as an independent variable and $K_{s s}=\left(K_{t t}\right)$ as the control variable indicates the change in $K_{n n}$ has a little effect on the analysis compared to $K_{s s}=\left(K_{t t}\right)$ as shown in Fig. 13. Thus, knowing the influence of $K_{n n}$ and $K_{s s}=\left(K_{t t}\right)$ on the analysis results, was defined as a certain value in the simulation for its little effect on the analysis results, and the value of $K_{s s}=\left(K_{t t}\right)$ was defined by numerical validation. Table 2 summarizes the penalty stiffness parameters determined for the final simulation.

The influence of varying the embedment depth of FRP rods was studied in the simulation with due consideration for the cohesive contact behavior to model the surface interaction between concrete and FRP rod (final simulation). The numerical result for the half-embedded (RTH) model showed an ultimate load of $42.55 \mathrm{kN}$ while edge-embedded (RTE) had $49.79 \mathrm{kN}$. Meanwhile, $58.97 \mathrm{kN}$ was achieved by the RTF model with a full-embedded depth of $14 \mathrm{~mm}$ considered to be the same with a depth of 1.5 of the rod diameters required by the code. These values clearly showed the ultimate load was increasing with an increment in the depth as observed in RTE and RTF having a corresponding increase of $17.03 \%$ and $37.66 \%$, respectively, compared to RTH while an enhancement of $17.63 \%$ was recorded between full-embedded (RTF) and edge-embedded (RTE) models. These findings underlined the results of the study conducted by Caro et al. [24] on the bond performance of deep embedment FRP bars epoxy-bonded into the concrete. The value of slip was also found to have increased with an increment in the FRP rod's embedment depth with the highest, $5.95 \mathrm{~mm}$, exhibited by the model with full-embedded FRP rod (RTF). Table 3 presents the summary of the result of the FE model with cohesive contact behavior.

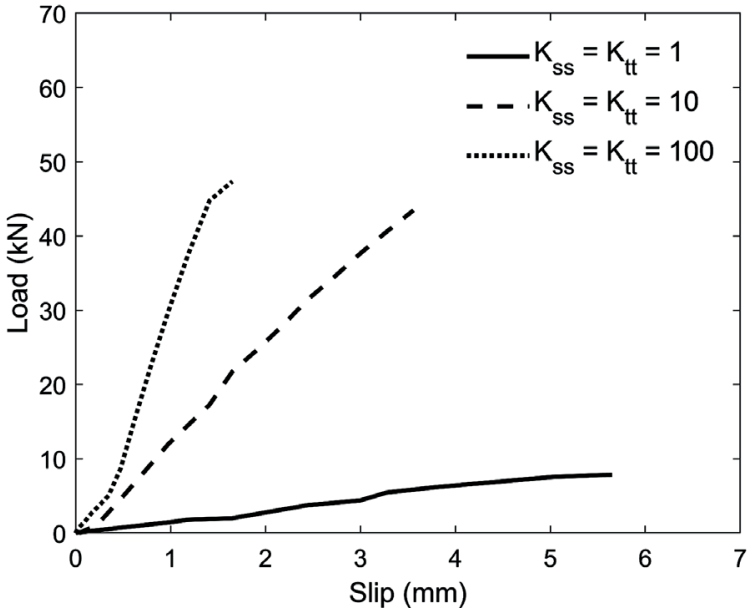

(a) RTH model

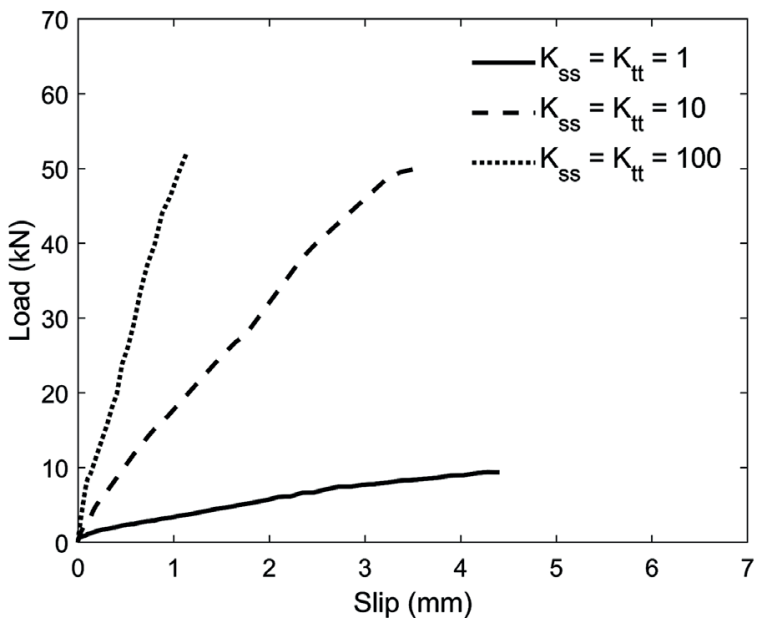

(b) RTE model

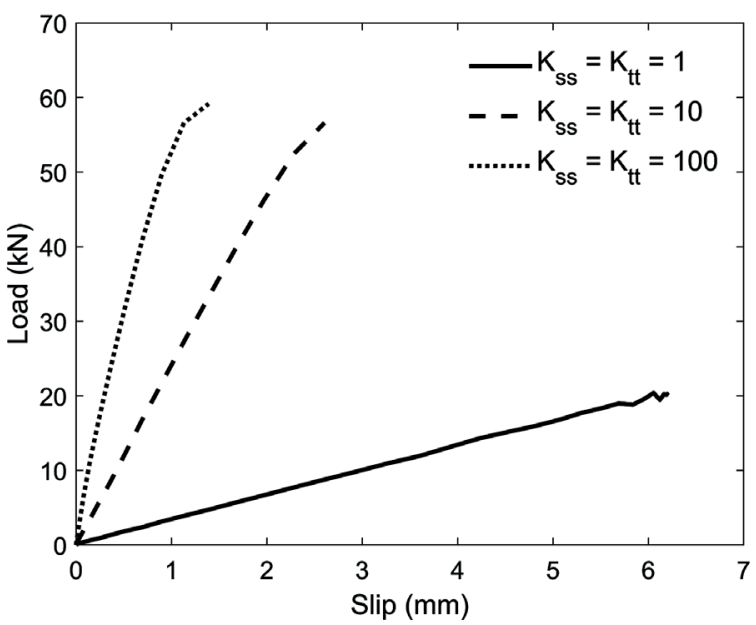

(c) RTF model

Fig. $12 K_{s s}=\left(K_{t t}\right)$ influence on the model

The results of the 3D final numerical simulations were analyzed and likened to the experimental findings in terms of applied load versus slip as depicted in Fig. 14 and the simulations were able to meet the experimental curves 


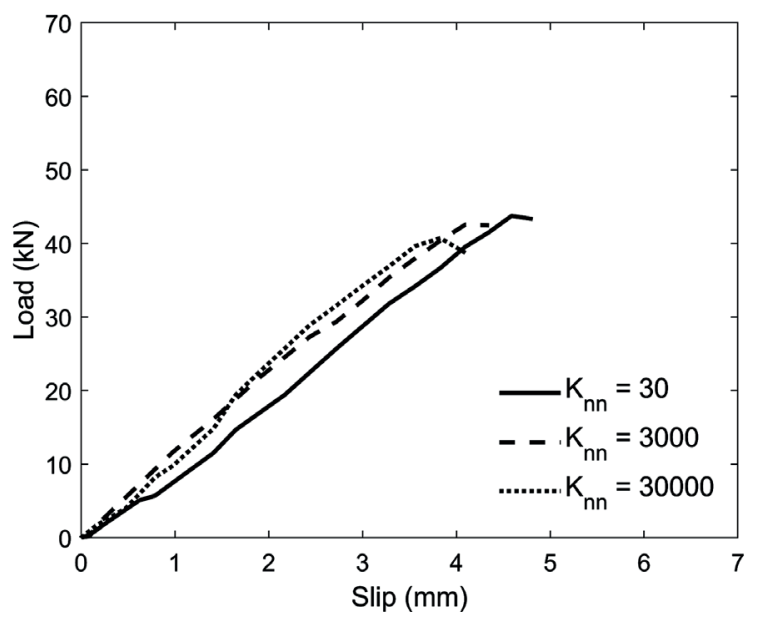

(a) RTH model

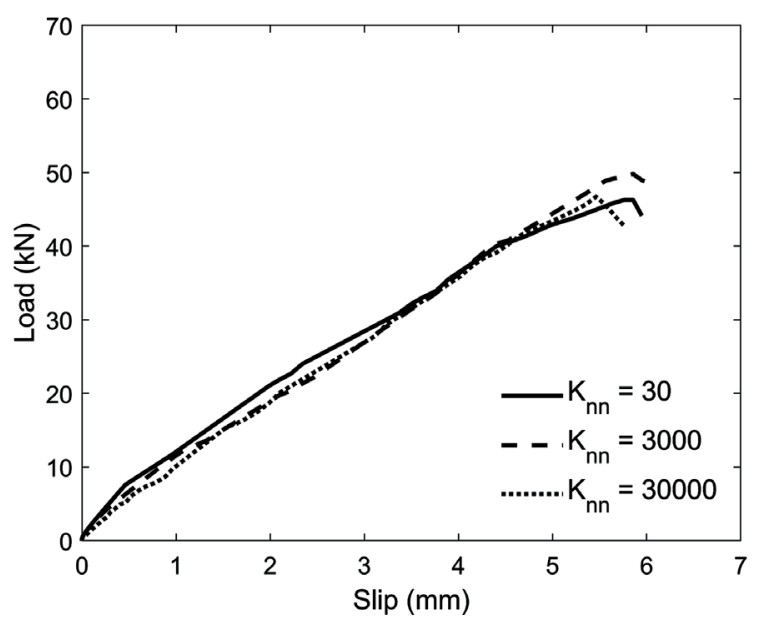

(b) RTE model

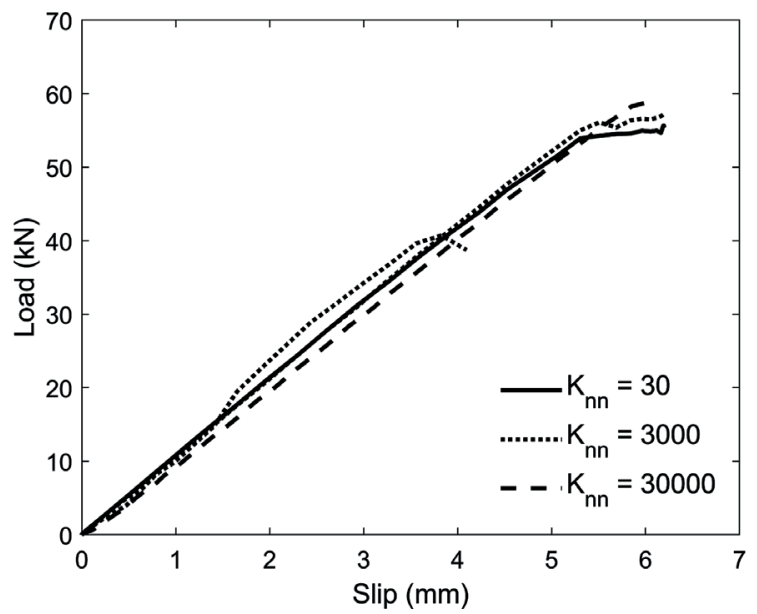

(c)

Fig. $13 K_{n n}$ influence on the model

Table 2 Penalty stiffness parameters for the final simulation

\begin{tabular}{lccc}
\hline Specimen & $K_{s s}\left(\mathrm{~N} / \mathrm{mm}^{3}\right)$ & $K_{t t}\left(\mathrm{~N} / \mathrm{mm}^{3}\right)$ & $K_{n n}\left(\mathrm{~N} / \mathrm{mm}^{3}\right)$ \\
\hline RTF & 3.5 & 3.5 & 3000 \\
RTE & 5 & 5 & 3000 \\
RTH & 8 & 8 & 3000 \\
\hline
\end{tabular}

Table 3 Results of the FE model with cohesive contact behavior

\begin{tabular}{lcc}
\hline Specimen & $\mathrm{P}_{\mathrm{u}(\mathrm{FE}-\mathrm{CB})}(\mathrm{kN})$ & $\operatorname{Slip}_{(\mathrm{FE}-\mathrm{CB})}(\mathrm{mm})$ \\
\hline RTH & 43.15 & 4.09 \\
RTE & 53.57 & 5.86 \\
RTF & 59.21 & 5.95 \\
\hline
\end{tabular}

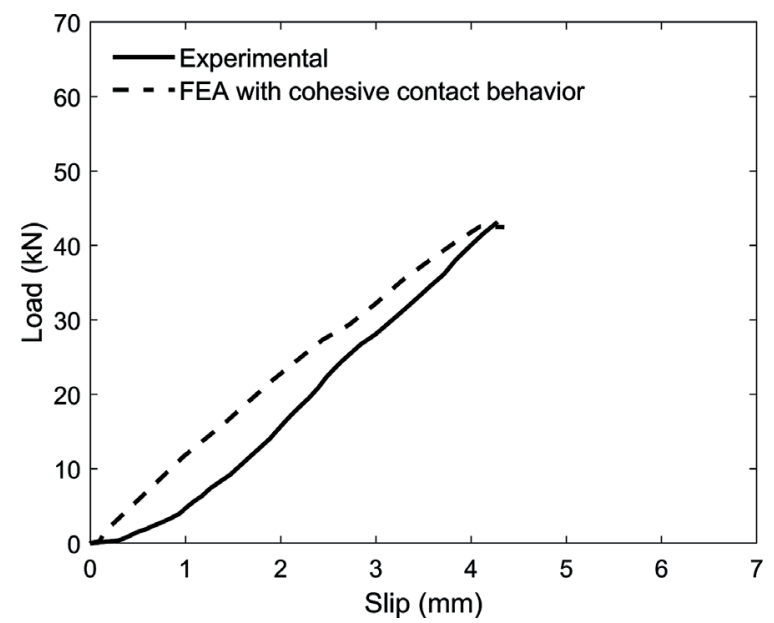

(a) RTH model

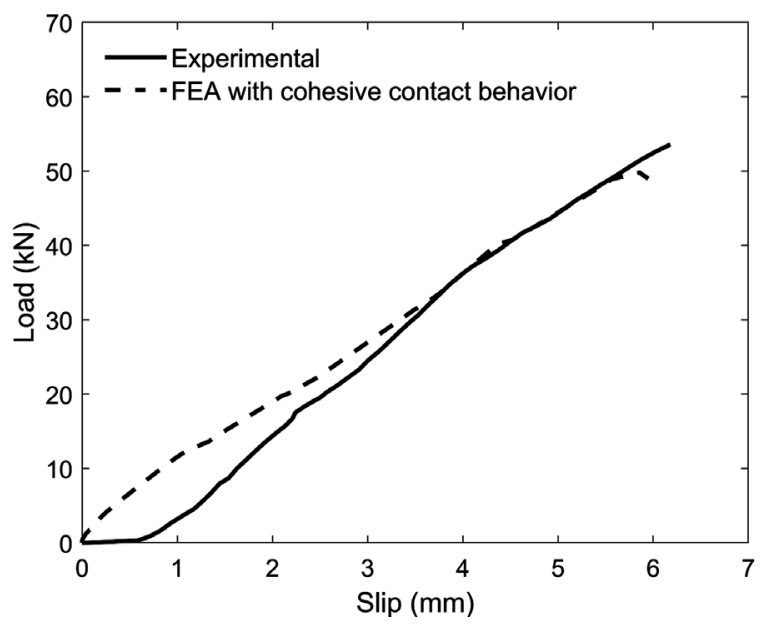

(b) RTE model

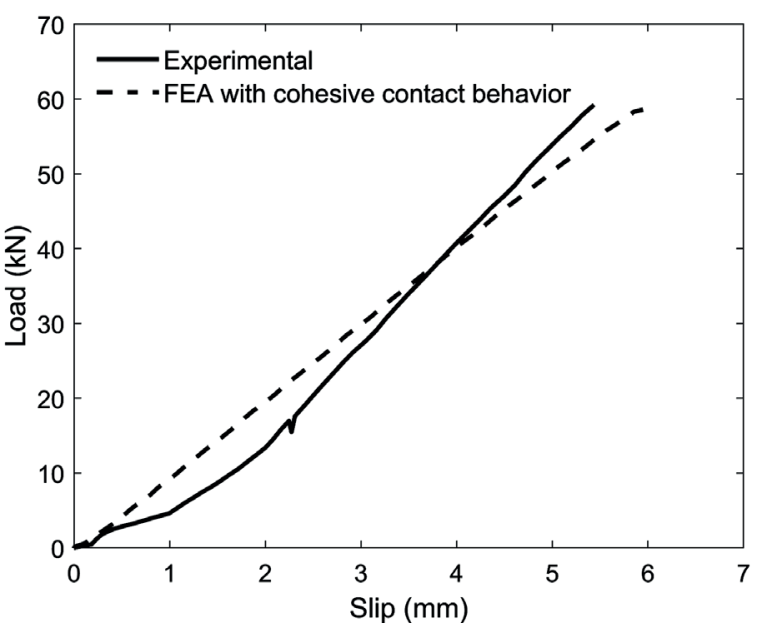

(c) RTF model

Fig. 14 Load versus slip for FE model with cohesive contact behavior 
Table 4 Experimental results vs FE model with cohesive contact behavior

\begin{tabular}{lcccccc}
\hline \multirow{2}{*}{ Specimen } & & Ultimate load & & \multicolumn{2}{c}{ Displacement } \\
& $\mathrm{P}_{\mathrm{u}(\mathrm{Exp})}(\mathrm{kN})$ & $\mathrm{P}_{\mathrm{u}(\mathrm{FE}-\mathrm{CB})}(\mathrm{kN})$ & Difference $(\%)$ & $\operatorname{Slip}_{(\mathrm{Exp})}(\mathrm{mm})$ & $\operatorname{Slip}_{(\mathrm{FE}-\mathrm{CB})}(\mathrm{mm})$ & Difference (\%) \\
\hline RTH & 43.15 & 48.92 & -1.43 & 4.28 & 4.09 & -4.48 \\
RTE & 53.57 & 57.37 & -7.59 & 6.18 & 5.86 & -5.51 \\
RTF & 59.21 & 61.83 & -1.09 & 5.44 & 5.95 & 8.61 \\
\hline
\end{tabular}

by considering the cohesive contact behavior to model the surface interaction between the concrete and FRP rod (Table 4). The implemented models were particularly able to follow all the applied loading stages up to failure as shown in the load-slip diagrams. Moreover, the final numerical results are very similar but, generally, showed a slightly lower value in the slip with an average of $0.46 \%$ difference while the ultimate load also demonstrated a bit lower peak with an average of $3.37 \%$ difference.

\subsection{Model behavior}

As previously reported by Budipriyanto et al. [22], the RTH specimen failed due to the loss of bond in the rodepoxy interface based on the small area of contact observed to by just one-half of the rod. Meanwhile, the RTE specimen failed in the concrete area adjacent to the rod and this is identical to what was observed with the RTF specimen. Therefore, the failure was unmistakable in the concrete area. Meanwhile, the 3D numerical analyses performed using the model described in Section 4.1 were unable to capture some important features in the experimental tests despite their ability to simulate the overall loading process effectively. The numerical simulations in Fig. 15 particularly showed no evidence of any stress concentration to suggest the mode of failure for the experimental specimens.

\subsection{Penalty stiffness parameter vs embedment depth}

This study only discussed the relationship between the penalty stiffness parameters in shear direction $K_{s s}=K_{t t}$ and the embedment depth of the FRP rod. This is due to the little effect of those in normal direction $K_{n n}$ on the simulation results and because they are set as an arbitrary fixed value in the simulation. Therefore, the defined values of the parameters in shear direction $K_{s s}=K_{t t}$ are shown in Fig. 16 after the comparison with the experimental data presented in Fig. 12. The results showed the relationship between the penalty stiffness parameters in shear direction $K_{s s}=K_{t t}$ and the embedment depth of FRP rods can be expressed using the following Eq. (2).
$K_{s S}=\left(K_{t t}\right)=3 r^{2}-12 r+15.3125$

where $r$ represents the ratio of embedment depth to the diameter of the FRP rod.

\section{Conclusions}

There was the development of a 3D FE numerical model to determine double shear lap tests performance for the bond of near-surface mounted FRP rods in concrete through the application of various embedment depth. The focus of this study was on two different approaches which include a numerical method with (a) perfect bond assumption and (b) consideration of cohesive contact behavior to model surface interaction between concrete and FRP rod. The results, therefore, showed the following:

- The use of the perfect bond model led to a prediction for failure load with reasonable agreement due to its $7.55 \%$ average disparity, but the results showed higher stiffness.

- The consideration of the cohesive contact behavior to model the surface interaction between concrete and FRP rod produced simulations which had a similar trend with the experimental curves.

- The final numerical results were very similar but generally showed a slightly lower value for the slip with an average difference of $0.46 \%$ and the ultimate load also had a bit lower peak with an average of difference $3.37 \%$.

- The pull-out capacity was improved by an increase in the embedded depth as observed in the corresponding increment of $17.03 \%$ and $37.66 \%$ for RTE and RTF respectively in comparison with the RTH.

- The numerical simulations showed no evidence of any stress concentration which suggests the mode of failure in the experimental specimens.

- The proposed model is able to express the relationship between the penalty stiffness parameters in shear direction $K_{s s}=K_{t t}$ and the embedment depth of FRP rods 

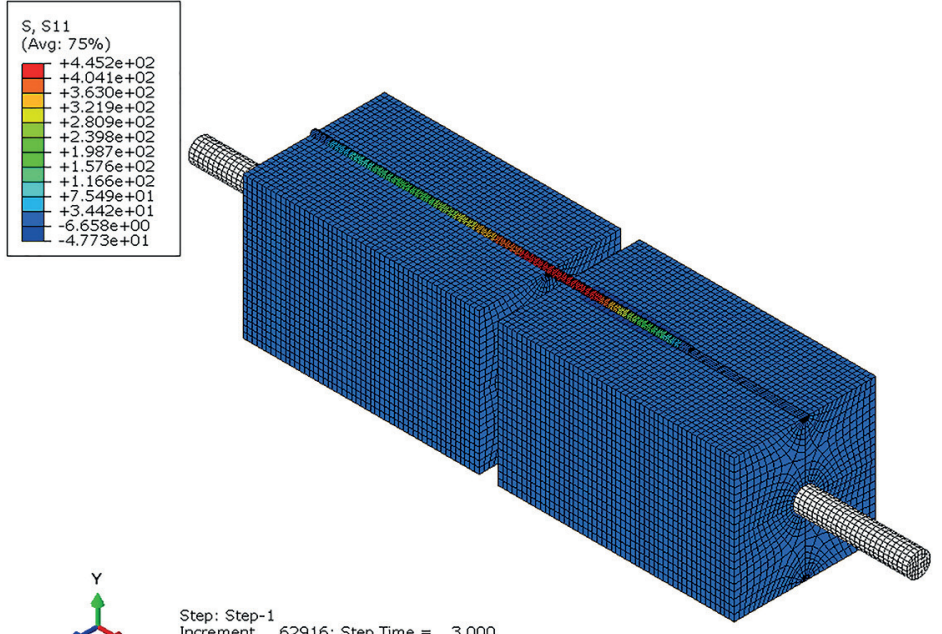

Step: Step-1
Increment $62916:$ Step Time $=3.000$
Primary Var: S, S11

(a) RTH model

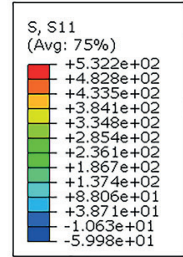

.

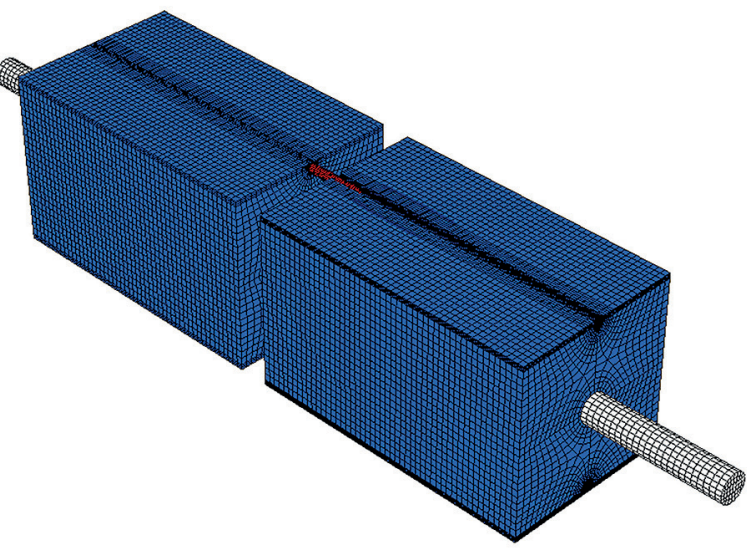

(b) RTE mode
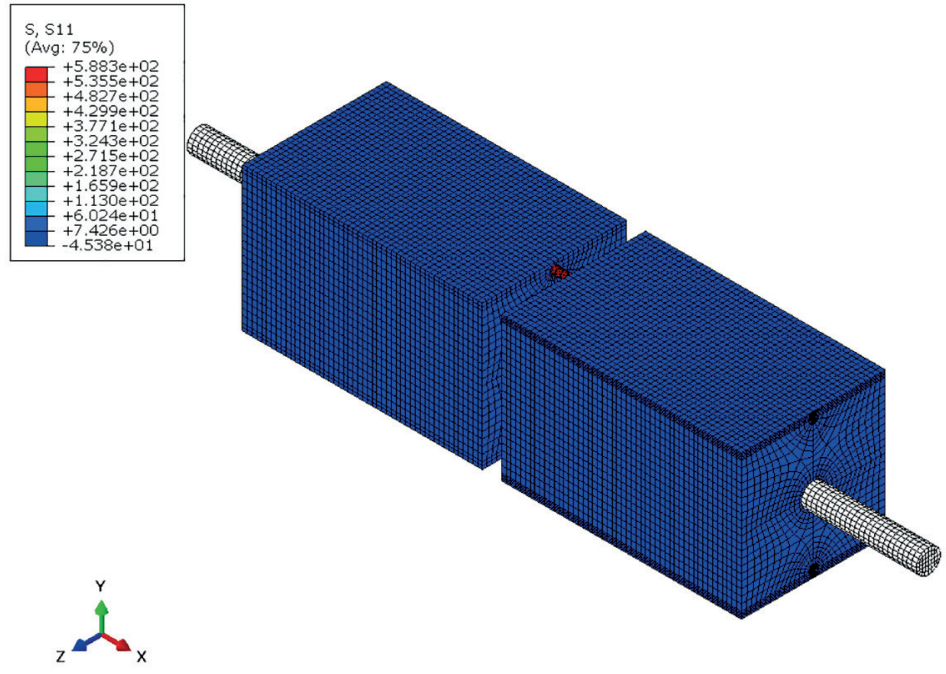

(c) RTF model
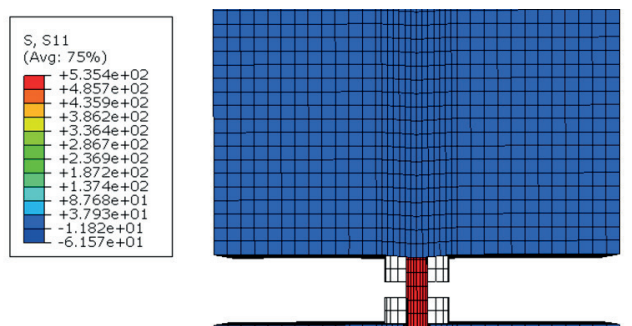

$z \leftarrow$

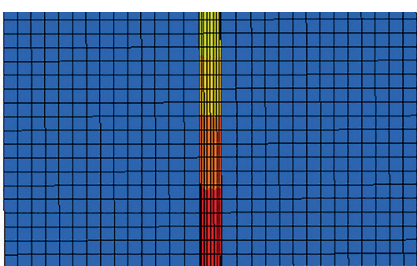

117
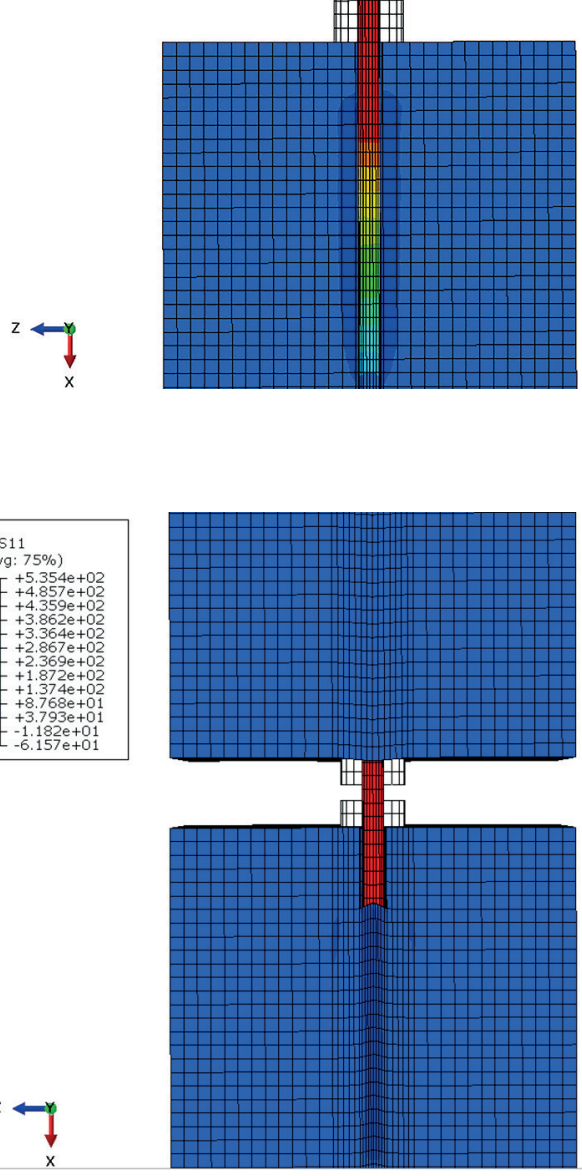

$z \leftarrow$
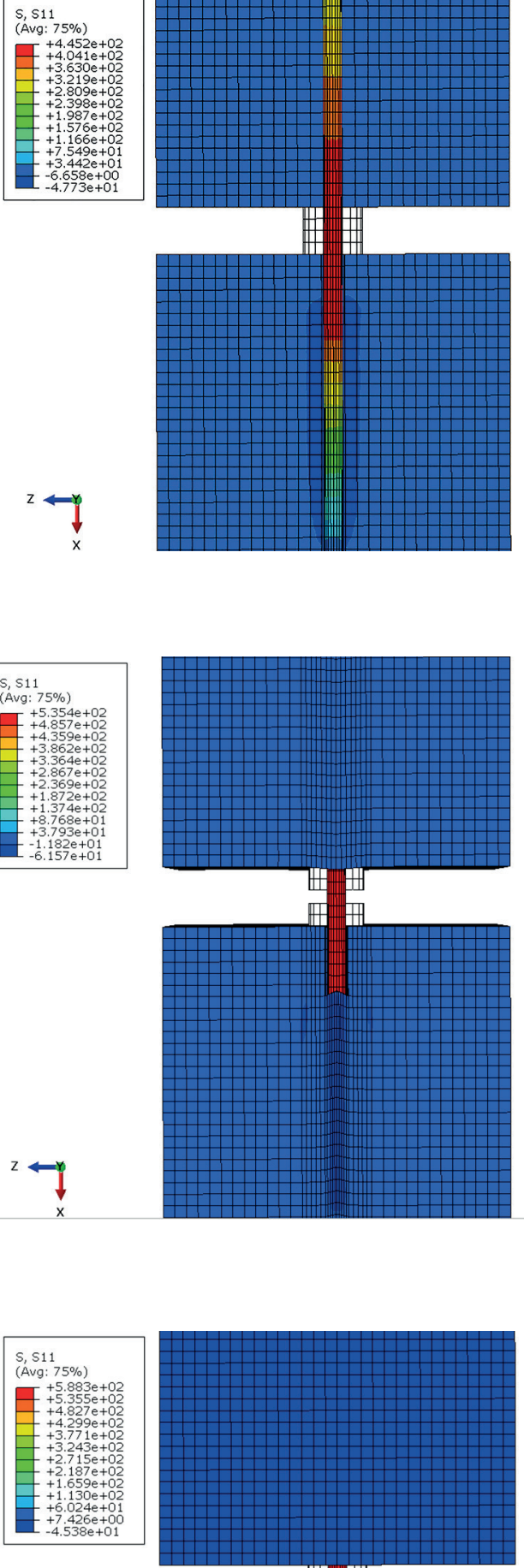

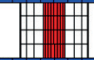

Fig. 15 Model behavior 


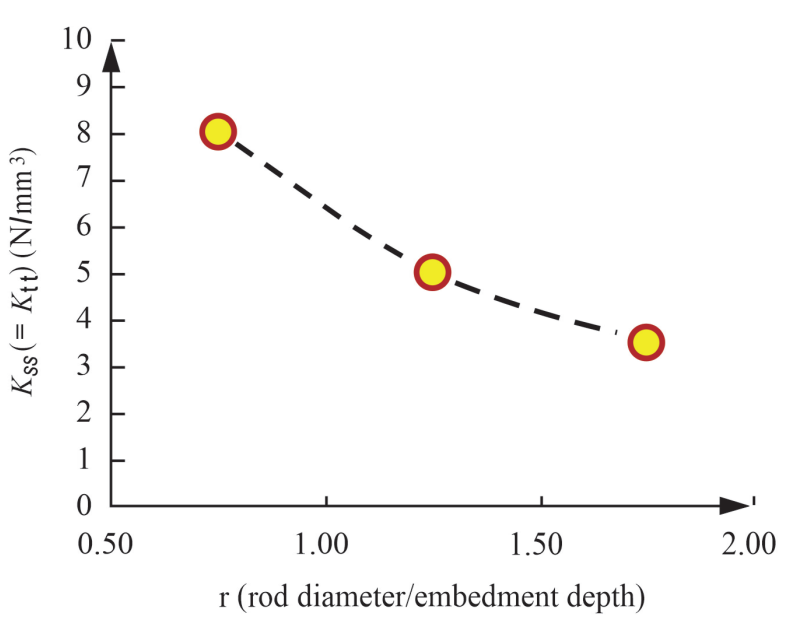

Fig. $16 K_{s s}=\left(K_{t}\right)$ vs embedment depth of FRP rods

\section{References}

[1] Toutanji, H. A., Gómez, W. "Durability characteristics of concrete beams externally bonded with FRP composite sheets", Cement and Concrete Composites, 19(4), pp. 351-358, 1997. https://doi.org/10.1016/S0958-9465(97)00028-0

[2] Mukhtar, F. M., Faysal, R. M. "A review of test methods for studying the FRP-concrete interfacial bond behavior", Construction and Building Materials, 169, pp. 877-887, 2018.

https://doi.org/10.1016/j.conbuildmat.2018.02.163

[3] Szabó, Z. K., Balázs, G. L. "Near surface mounted FRP reinforcement for strengthening of concrete structures", Periodica Polytechnica Civil Engineering, 51(1), pp. 33-38, 2007.

https://oi.org/10.3311/pp.ci.2007-1.05

[4] Wang, J., GangaRao, H., Liang, R., Liu, W. "Durability and prediction models of fiber-reinforced polymer composites under various environmental conditions: A critical review", Journal of Reinforced Plastics and Composites, 35(3), 179-211, 2016.

https://doi.org/10.1177/0731684415610920

[5] Sharaky, I. A., Torres, L., Comas, J., Barris, C. "Flexural response of reinforced concrete (RC) beams strengthened with near surface mounted (NSM) fibre reinforced polymer (FRP) bars", Composites Structures, 109, pp. 8-22, 2014.

https://doi.org/10.1016/j.compstruct.2013.10.051

[6] Barris, C., Sala, P., Gómez, J., Torres, L. "Flexural behaviour of FRP reinforced concrete beams strengthened with NSM CFRP strips", Composites Structures, 241, Article No. 112059, 2020.

https://doi.org/10.1016/j.compstruct.2020.112059

[7] Abdallah, M., Al Mahmoud, F., Khelil, A., Mercier, J., Almassri, B. "Assessment of the flexural behavior of continuous RC beams strengthened with NSM-FRP bars, experimental and analytical study", Composites Structures, 242, Article No. 112127, 2020. https://doi.org/10.1016/j.compstruct.2020.112127

[8] Jalali, M., Sharbatdar, M. K., Chen, J.-F., Alaee, F. J. "Shear strengthening of RC beams using innovative manually made NSM FRP bars", Construction and Building Materials, 36, pp. 990-1000, 2012.

https://doi.org/10.1016/j.conbuildmat.2012.06.068

\section{Conflict of interest}

The authors declare no conflicts of interest.

\section{Acknowledgment}

The fund for this study was provided by the Ministry of Science and Technology, Taiwan (R.O.C) through the grant number MOST-108-2625-M-006-006. The first author, however, show gratitude to the Ministry of Education, Taiwan (R.O.C) as well as the CTCI Foundation for the support provided through the Elite Scholarship and the Research Scholarship for International Graduate Students, respectively.

[9] Al-Mahmoud, F., Castel, A., Minh, T. Q., François, R. "Reinforced Concrete Beams Strengthened with NSM CFRP Rods in Shear", Advances in Structural Engineering, 18(10), pp. 1563-1574, 2015. https://doi.org/10.1260/1369-4332.18.10.1563

[10] Echeverria, M., Perera, R. "Three dimensional nonlinear model of beam tests for bond of near-surface mounted FRP rods in concrete", Composites Part B: Engineering, 54, pp. 112-124, 2013. https://doi.org/10.1016/j.compositesb.2013.05.008

[11] Novidis, D. G., Pantazopoulou, S. J. "Bond Tests of Short NSM-FRP and Steel Bar Anchorages", Journal of Composites for Construction, 12(3), pp. 323-333, 2008. https://doi.org/10.1061/(ASCE)1090-0268(2008)12:3(323)

[12] Bilotta, A., Ceroni, F., Di Ludovico, M., Nigro, E., Pecce, M., Manfredi, G. "Bond Efficiency of EBR and NSM FRP Systems for Strengthening Concrete Members", Journal of Composites for Construction, 15(5), pp. 757-772, 2011. https://doi.org/10.1061/(ASCE)CC.1943-5614.0000204

[13] Ceroni, F., Pecce, M., Bilotta, A., Nigro, E. "Bond behavior of FRP NSM systems in concrete elements", Composites Part B: Engineering, 43, pp. 99-109, 2012. https://doi.org/10.1016/j.compositesb.2011.10.017

[14] Seo, S.-Y., Feo, L., Hui, D. "Bond strength of near surface-mounted FRP plate for retrofit of concrete structures", Composite Structures, 95, pp. 719-727, 2013. https://doi.org/10.1016/j.compstruct.2012.08.038

[15] Yun, Y., Wu, Y.-F., Tang, W. C. "Performance of FRP bonding systems under fatigue loading", Engineering Structures, 30(11), pp. 3129-3140, 2008. https://doi.org/10.1016/j.engstruct.2008.04.026

[16] De Lorenzis, L., Nanni, A. "Bond Between Near Surface Mounted FRP Rods and Concrete in Structural Strengthening", ACI Structural Journal, 99(2), 123-132, 2002.

[17] de Sena Cruz, J. M., de Barros, J. A. O. "Bond Between NearSurface Mounted Carbon-Fiber-Reinforced Polymer Laminate Strips and Concrete", Journal of Composites for Construction, 8(6), pp. 519-527, 2004. https://doi.org/10.1061/(ASCE)1090-0268(2004)8:6(519) 
[18] De Lorenzis, L., Rizzo, A., La Tegola, A. "A modified pull-out test for bond of near-surface mounted FRP rods in concrete", Composites Part B: Engineering, 33(8), pp. 589-603, 2002. https://doi.org/10.1016/S1359-8368(02)00052-5

[19] Novidis, D., Pantazopoulou, S. J., Tentolouris, E. "Experimental study of bond of NSM-FRP reinforcement", Construction and Building Materials, 21, pp. 1760-1770, 2007. https://doi.org/10.1016/j.conbuildmat.2006.05.054

[20] ACI "ACI 440.2R-08 Guide for the design and construction of externally bonded FRP systems for strengthening concrete structures", American Concrete Institute, Farmington Hills, MI, USA, 2008.

[21] Sapulete, C. A. "Studi eksperimental pengaruh perkuatan lentur fiber reinforced polymer pada balok dan efektivitasnya" (Experimental study on the effect of fiber reinforced polymer as a flexural strengthening on the beams and its effectiveness), Master Thesis, Diponegoro University, 2018. (in Indonesian)

[22] Budipriyanto, A., Han, A. L., Hu, H. T. "Bond-shear Behavior of FRP Rods as a Function of Attachment Configuration", Journal of Advanced Civil and Environmental Engineering, 1(1), pp. 9-17, 2018. https://doi.org/10.30659/jacee.1.1.9-17

[23] Han, A., Gan, B. S., Budipriyanto, A. "Shear-bond behavior of fiber reinforced polymer (FRP) rods and sheets", MATEC Web of Conferences, 195, Article No. 02001, 2018. https://doi.org/10.1051/matecconf/201819502001

[24] Caro, M., Jemaa, Y., Dirar, S., Quinn, A. "Bond performance of deep embedment FRP bars epoxy-bonded into concrete", Engineering Structures, 147, pp. 448-457, 2017. https://doi.org/10.1016/j.engstruct.2017.05.069

[25] Biolzi, L., Ghittoni, C., Fedele, R., Rosati, G. "Experimental and theoretical issues in FRP concrete bonding", Construction and Building Materials, 41, pp. 182-190, 2013. https://doi.org/10.1016/j.conbuildmat.2012.11.082

[26] Dassault Systèmes "Abaqus 6.11: Theory Manual", Dassault Systèmes, Providence, RI, USA, 2011.

[27] Lubliner, J., Oliver, J., Oller, S., Oñate, E. "A plastic-damage model for concrete", International Journal of Solids and Structures, 25(3), pp. 299-326, 1989. https://doi.org/10.1016/0020-7683(89)90050-4
[28] ACI "ACI 318-14 Building code requirements for structural concrete and commentary", American Concrete Institute, Farmington Hills, MI, USA, 2014.

[29] Hognestad, E., Hanson, N. W., McHenry, D. "Concrete Stress Distribution in Ultimate Strength Design", ACI Journal Proceedings, 52(12), pp. 455-480, 1955. https://oi.org/10.14359/11609

[30] Vecchio, F. J., Collins, M. P. "The Modified Compression-Field Theory for Reinforced Concrete Elements Subjected to Shear", ACI Journal Proceedings, 83(2), pp. 219-231, 1986.

https://doi.org/10.14359/10416

[31] Hsu, T. T. C. "Toward A Unified Nomenclature for ReinforcedConcrete Theory", Journal of Structural Engineering, 122(3), pp. 275-283, 1996. https://doi.org/10.1061/(ASCE)0733-9445(1996)122:3(275)

[32] Belarbi, A., Hsu, T. T. C. "Constitutive Laws of Concrete in Tension and Reinforcing Bars Stiffened By Concrete", ACI Structural Journal, 91(4), pp. 465-474, 1994. https://doi.org/10.14359/4154

[33] Genikomsou, A. S., Polak, M. A. "Finite element analysis of punching shear of concrete slabs using damaged plasticity model in ABAQUS", Engineering Structures, 98, pp. 38-48, 2015. https://doi.org/10.1016/j.engstruct.2015.04.016

[34] Raza, A., Khan, Q. u. Z., Ahmad, A. "Numerical Investigation of Load-Carrying Capacity of GFRP-Reinforced Rectangular Concrete Members Using CDP Model in ABAQUS", Advances in Civil Engineering, 2019, Article ID 1745341, 2019. https://doi.org/10.1155/2019/1745341

[35] Al-Zaid, R. Z., Al-Negheimish, A. I., Al-Saawani, M. A., El-Sayed, A. K. "Analytical study on RC beams strengthened for flexure with externally bonded FRP reinforcement", Composites Part B: Engineering, 43(2), 129-141, 2012. https://doi.org/10.1016/j.compositesb.2011.11.015 